\title{
Insights into preformed HSA corona on iron oxide nanoparticles: structure, effect of particle size, impact on MRI efficiency and metabolization
}

\author{
Carlos Moya ${ }^{1}$, Remei Escuderoํ․ David C Malaspina ${ }^{1}$, Maria de la Mata ${ }^{2}$, Jesús \\ Hernández-Saz ${ }^{3}$, Jordi Faraudo ${ }^{1}$, Anna Roig ${ }^{1^{\star}}$ \\ ${ }^{1}$ Institut de Ciència de Materials de Barcelona (ICMAB-CSIC), Campus UAB, 08193 Bellaterra, \\ Spain, corresponding autor: roig@icmab.es \\ ${ }^{2}$ Departamento de Ciencia de los Materiales e Ing. Met. y Q. I. IMEYMAT. Universidad de Cádiz. \\ Campus Río San Pedro, 11510 Puerto Real, Spain \\ ${ }^{3}$ Departamento. de Ingeniería y Ciencia de los Materiales y del Transporte, Universidad de \\ Sevilla, 41092 Sevilla, Spain
}

\begin{abstract}
In the last decade there has been profuse research efforts exploring the uses of iron oxide particles in nanomedicine. To a great extent, the efficiency of magnetic iron oxide nanoparticles for biomedical applications and the nanoparticles fate depend on how the nanoparticle surface interfaces with the proteins in a physiological environment. It is well reported how ungoverned protein corona can be detrimental for cellular uptake and targeting efficiency and how it can modify the nanoparticles biodistribution.

Novel strategies are emerging to achieve enhanced and more reproducible performances of engineered nanoparticles with a custom-built protein corona. Here we report on a generalized protocol to preform a monolayer of human serum albumin (HSA) on superparamagnetic iron oxide nanoparticles (SPIONs) of different sizes. The resulting molecular structure is described by molecular dynamics simulations of the hybrid nanoconjugates. The number of proteins forming the corona and their disposition as a monolayer on the particle surface predicted by molecular simulations is in agreement with the results obtained from dynamic light scattering and electronic microscopy analysis. Moreover, by tryptophan fluorescence quenching, we determine a strong interaction between the SPIONs and the HSA endorsing the robustness of the proteinnanoparticles conjugates in this system. Besides, the effect of the HSA corona on the SPIONs efficiency as magnetic resonance imaging (MRI) contrast agents in water, human serum and in saline medium has been evaluated. The protein corona did not affect the efficiency of the SPIONs as $T_{2}$ contrast agents but reduce their efficiency as $T_{1}$. In addition, we observed a greater stability for HSA-SPIONs nanoconjugates in saline and in acid media preventing nanoparticle dissolution in extreme gastric conditions.
\end{abstract}

Keywords: Human Serum Albumin, Superparamagnetic Iron Oxide Nanoparticles, Albumin Corona, Magnetic Resonance Imaging, Metabolization 


\section{Introduction}

Superparamagnetic iron oxide nanoparticles (SPIONs), which become magnetized only under the presence of an external magnetic field, have found utility in many in vitro and in vivo biomedical applications. ${ }^{1}$ Specifically, SPIONs are used as longitudinal ${ }^{2,3}$ and transverse magnetic resonance imaging (MRI) contrast agents, ${ }^{4}$ in cell labeling, ${ }^{5}$ cell sorting ${ }^{6}$ or cell therapy, ${ }^{7}$ as drug delivery carriers ${ }^{8}$ and in thermotherapy for oncological treatments. ${ }^{9,10}$

The efficiency of iron oxide nanoparticles for the intended application as well as the particles fate will largely depend on how the nanoparticle surface interacts with the proteins present in a given physiological environment. In a bio-relevant milieu, the formation and time evolution of the protein corona resulting from the biomolecules adsorption on the nanoparticles surface can be extremely diverse and dynamic over time. ${ }^{11}$ This ungoverned protein corona is regulated by many parameters, among others, the nanoparticle size and the composition of its surface, its blood circulation time or the $\mathrm{pH}$ of the biological microenvironment. Complex competitive and/or cooperative adsorption processes between different proteins are present in ungoverned protein corona formed in biological media, which make extremely difficult to predict the composition and structure of the resulting hybrid material. ${ }^{12}$ In the last years, it has been intensively reported how this acquired protein corona impacts on the nanoparticles performance. ${ }^{13}$ The protein corona influences the nanoparticles aggregation, ${ }^{14}$ cellular uptake, ${ }^{14}$ decrease of targeting efficiency, ${ }^{15}$ biodistribution, ${ }^{16,17}$ MRI efficiency, ${ }^{18,19}$ hyperthermia performance ${ }^{19}$ or in vivo nanoparticle biodegradation, ${ }^{20}$ just to name a few.

Novel strategies are currently emerging to take advantage of the protein coating. The rationale behind is that better reproducibility and enhanced performance could be expected from engineered nanoparticles with custom-built protein corona in opposition to the problems associated with the formation of an protein corona. Preforming coronas can be achieved by fabricating strongly-bonded protein-inorganic core nanoconjugates in a controlled and reproducible fashion. For instance, the work by Oh et al. ${ }^{21}$ presents an example of proteinnanoparticle hybrids maintaining targeting ability. Others showed that preformed protein corona enables more control over cellular interactions ${ }^{22,23}$ and serves as a protective coating for nanoparticles-based drug delivery systems. ${ }^{24,25}$ Moreover, atomistic simulation methodologies are currently being developed able to predict the structure of preformed protein corona for those proteins with known structures. ${ }^{26,27}$

To establish general protocols on preforming protein coronas onto particles of different sizes or compositions it is crucial to have good modelling tools to simulate these hybrid nanoconjugates as well as experimental protocols to monitor the quality of the preformed corona, its reproducibility, time stability and impact on the sought-after biomedical uses. To this end, SPIONs have been used here as a model system. We previously reported the large binding constant of bovine serum albumin (BSA)-SPIONs ${ }^{28}$ and the investigation of their in vivo fate in the C. elegans model. ${ }^{29}$

To generalize such approach, here, we have synthetized SPIONs of three different sizes and bio-shielded them with a monolayer of human serum albumin (HSA) foreseeing potential clinical translation of the nanoconjugates. The structural and physico-chemical characteristics of three systems are then reported. The number of HSA proteins adsorbing onto particles of different sizes and the structure of the protein corona has been studied theoretically by all-atomic molecular dynamics (MD) simulations and quantitatively confirmed experimentally. Moreover, since SPIONs are extensively used as in vitro and in vivo MRI contrast agents, the impact of the preformed protein coating on the MRI relaxivity values $\left(\mathrm{r}_{1}\right.$ and $\mathrm{r}_{2}$ ) has been evaluated in water, human plasma and phosphate-buffered saline (PBS) for short and long storage times. Finally, size 
dependent metabolization kinetics of protein-coated and uncoated nanoparticles in acid media has been established and we have explored the formation albumin cages using the iron oxide cores as sacrificial templates.

\section{Results and Discussion}

Citrate-coated SPIONs, simply referred here as SPIONs, of three different diameters have been synthesized by a fast microwave-assisted thermal decomposition method with some modifications from our previously reported route. ${ }^{28}$ Particle synthesis is described with detail in the Experimental Section. Figures 1a-c depict transmission electron microscopy (TEM) images of rounded shaped polyhedrical nanoparticles with mean diameters of $4.0 \pm 0.9 \mathrm{~nm}$ (S4), $5.7 \pm$ $0.9 \mathrm{~nm}$ (S6) and $9.4 \pm 1.7 \mathrm{~nm}$ (S9). Particle size distribution histograms are depicted in Figure S1 of the Supplementary Information (SI). Insets of Figure 1 contain selected area electron diffraction (SAED) patterns, which were indexed to the iron inverse spinel structure of maghemite. The lower inset of Figure 1c contains an atomic resolution Z-contrast image of the three selected NPs shown in Figure 1d. The violet framed NP shows an interplanar spacing, $d$, of $5.96 \AA$, in good agreement with the $\{110\}$ plane of maghemite crystal structure (see the (hkl) distances included in Figure 1d). Orange and green framed NPs are oriented along the [112] and [110] zone axis, respectively, and their indexed fast-Fourier transforms are also included. Lower panels (Figures 1e-g) show single modal dynamic light scattering (DLS) volume-weighted size histograms with a PdI values around 0.18 (S4=0.17; S6= 0.19 and S9=0.17), confirming the good stability of the samples in water and discarding the presence of large aggregates. As expected for citrate-coated SPIONs, $\zeta$-potential for all samples are negative (-41 $\pm 4 \mathrm{mV} \mathrm{S4},-35$ $\pm 3 \mathrm{mV}$ S6 and $-30 \pm 2 \mathrm{mV}$ S9).
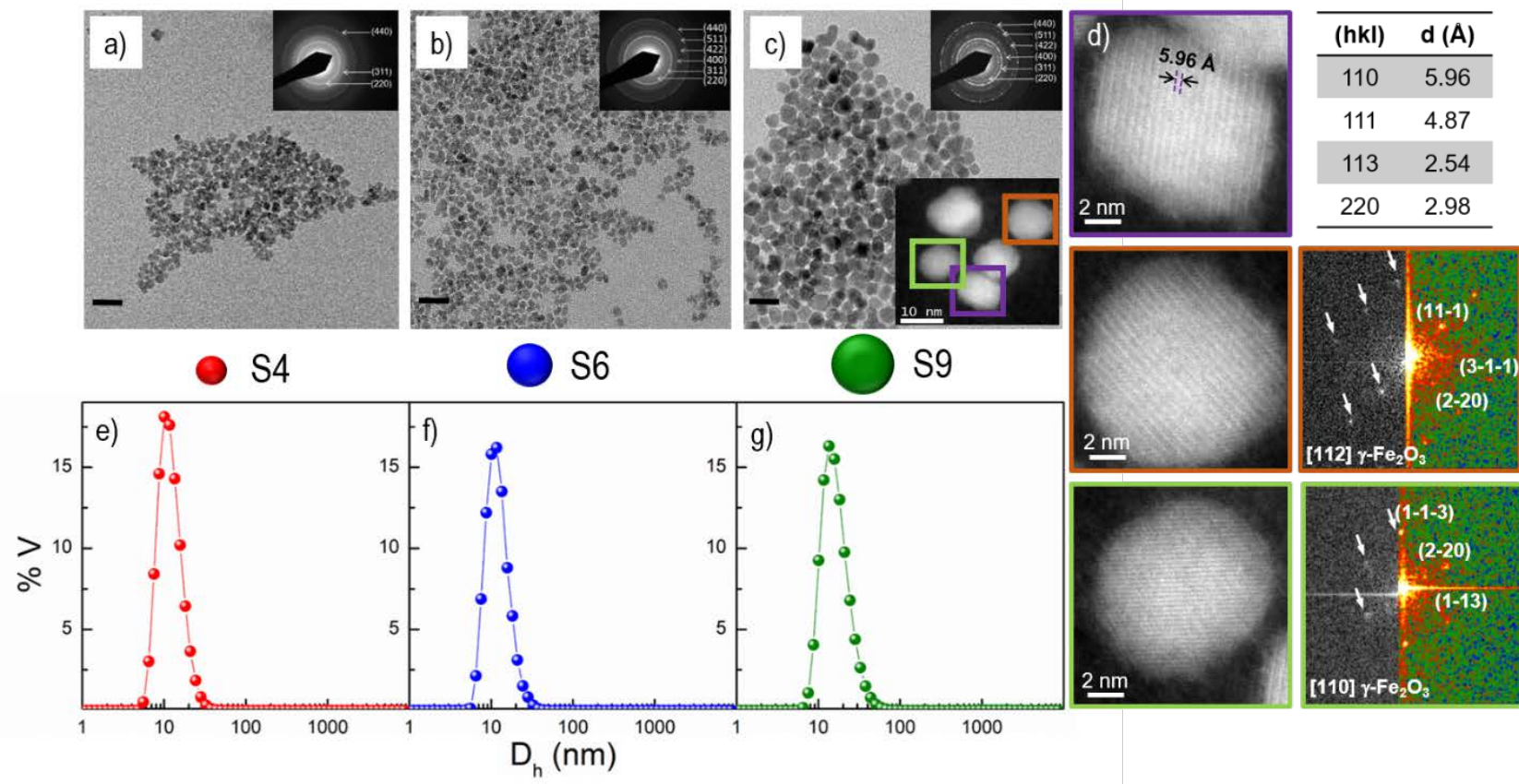

Figure 1. Structural characterization. TEM images for a) S4, b) S6 and c) S9. Scale bar is $20 \mathrm{~nm}$ in all images. SAED indexed to inverse spinel structure (upper insets). Lower inset for Fig 1c shows a Z-contrast image of some nanoparticles that are magnified and indexed in d). e)-g) DLS volume-weighted diameter histograms for samples dispersed in aqueous media. 
Table 1 gathers the nanoparticles structural and magnetic properties of samples dispersed in water (saturation magnetization, $\mathrm{M}_{\mathrm{s}}$, and blocking temperature, $\mathrm{T}_{\mathrm{B}}$ ). Magnetic measurements show typical features of a superparamagnet. No remanence of the hysteresis loops, $M(H)$ at 300 $\mathrm{K}$ and a clear peak in the $\mathrm{M}(\mathrm{T})$ zero-field curves (Figures S2 a,b) are observed. As expected, both $M_{s}$ and $T_{B}$ increase with the particle volume (see Table 1). Note that larger values of $M_{s}$ correspond to S9, likely not only due to their larger volume but also to better crystallinity resulting from a longer time at higher temperature during the synthesis.

Table 1. Structural and magnetic properties for SPIONs dispersed in aqueous media.

\begin{tabular}{|c|c|c|c|c|c|c|}
\hline SPIONs & $\begin{array}{c}\mathrm{D}_{\text {TEM }} \\
(\mathrm{nm})\end{array}$ & $\begin{array}{c}\mathrm{DLS} \\
(\mathrm{nm})\end{array}$ & Pdl & $\begin{array}{c}\zeta \text {-potential } \\
(\mathrm{mV})\end{array}$ & $\begin{array}{c}\mathrm{M}_{\mathrm{s}} \text { at } 300 \mathrm{~K} \\
(\mathrm{emu} / \mathrm{g})\end{array}$ & $\begin{array}{c}\mathrm{T}_{\mathrm{B}} \\
(\mathrm{K})\end{array}$ \\
\hline $\mathrm{S} 4$ & $4.0 \pm 0.9$ & $10 \pm 4$ & 0.17 & $-45 \pm 4$ & 45 & 27 \\
\hline $\mathrm{S} 6$ & $5.7 \pm 0.9$ & $11 \pm 4$ & 0.19 & $-35 \pm 3$ & 51 & 31 \\
\hline $\mathrm{S} 9$ & $9.4 \pm 1.7$ & $14 \pm 5$ & 0.17 & $-30 \pm 2$ & 70 & 100 \\
\hline
\end{tabular}

The choice here of human serum albumin (HSA) to preform a protein corona has several justifications. HSA is extremely robust with respect to $\mathrm{pH}$ and temperature changes and is stable in both organic and aqueous media. ${ }^{30}$ Moreover, albumin has a vital physiological role in the transport of fatty acids and in the maintenance of the osmotic pressure in the blood vessel. Finally, HSA has demonstrated great efficacy in anticancer drug formulations; the methotrexate-albumin conjugate (MTX-HSA), ${ }^{31}$ albumin-doxorubicin (DOXO-EMCH) ${ }^{32}$ and albumin paclitaxel (Abraxane).$^{33}$ Here, the HSA coating was done similarly to our previously reported BSA protocol, ${ }^{28}$ but being very thorough during the cleaning step to avoid free protein in solution and to ensure the reproducibility of the coating by a single protein layer (see albumin forming corona in Experimental Section). In Figure 2a, we evaluate the increment of particle diameter upon HSA incubation for $1 \mathrm{~h}$ for concentrations ranging from 0 to $76.5 \mu \mathrm{M}$ in a solution of SPIONs (3.1 $\mathrm{mM}$ ). In all cases, the final size reached an increment $\Delta \mathrm{D} \sim 7 \mathrm{~nm}$ that is twice the size of the albumin protein, indicating that interaction of the albumin with the citrate coated SPIONs is through the flat side of the protein. We then consider $35 \mu \mathrm{M}$ of HSA as the concentration needed to coat the particle surface entirely. Figure S3 contains zeta average hydrodynamic histograms showing the hydrodynamic diameter increment at different HSA concentrations. The HSASPIONs nanoconjugates are identified as HSA-S4, HSA-S6 and HSA-S9. $\zeta$-potential of the nanoconjugates in aqueous media are very similar regardless particle size pointing to an homogeneous HSA coating (-35 \pm 3 mV HSA-S4, $-35 \pm 4$ mV HSA-S6 and $-34 \pm 4$ mV HSAS9).

Figure $2 \mathrm{~b}$ depicts a negative staining TEM image for the HSA-S9 sample where the uranyl stained protein is shown brighter. The nanoparticles (dark contrast) exhibit single homogeneous shells with thicknesses of $\sim 3 \pm 1 \mathrm{~nm}$. Note that white spots in the image are due to the differences in uranyl acetate concentration on the TEM grid. Figure S4 shows a negative TEM image for the HSA-S6 system showing similar features. 

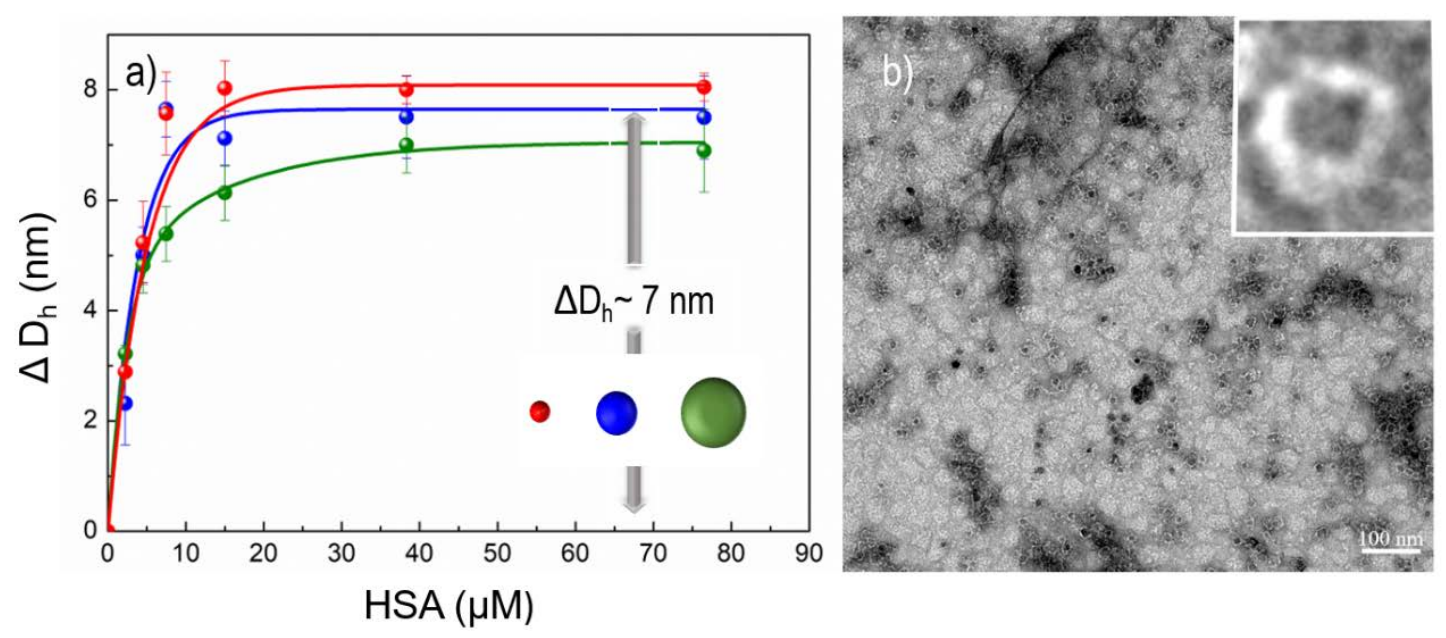

Figure 2. a) Monitoring zeta average hydrodynamic diameter (measured by DLS) as a function of the HSA concentration for the three systems S4 (red), S6 (blue) and S9 (green). b) TEM negative staining image of sample S9. Inset shows a single nanoparticle. A protein corona of approx. 3nm thickness is surrounding (white contrast) the inorganic core (dark contrast).

Next, we embarked on a theoretical study of the disposition and expected number of proteins for the preformed protein corona of nanoparticles of different sizes. To this end, we employed implicit solvent all-atomic molecular dynamics (MD) simulations, a tool successfully employed to study the formation of protein corona (and protein monolayers over nanomaterials in general) in previous studies, ${ }^{26,28}$ We performed simulations at room temperature of the adsorption of HSA over nanoparticles with sizes of 3, 6 and $9 \mathrm{~nm}$ (these simulations are labelled as MD3, MD6 and MD9, respectively). For the HSA we employed the atomistic structure available at the Protein Data Bank code PDB:1e78 (all technical details are described in the Methods Section).

Firstly, we determined the number of proteins forming the corona for nanoparticles with sizes of 3, 6 and $9 \mathrm{~nm}$. In all cases, we obtained a protein monolayer (in agreement with TEM observations) which was formed by 3, 10 and 30 proteins, respectively (Figure 3). These results are in excellent agreement with the experimental results determined from the fluorescence spectra of the supernatants after serial centrifugations (see Figures 3 and S5). Interestingly, the number of HSA proteins obtained in simulation MD6 (for a $6 \mathrm{~nm} \mathrm{NP}$ ) is the same than previously obtained for BSA over a NP with the same diameter. ${ }^{28}$ These numbers of adsorbed proteins correspond to very similar surface coverages for the three particles. Taking into account the area of the NP surface, we obtain a coverage of 0.11 proteins $/ \mathrm{nm}^{2}$ for MD3, 0.09 proteins $/ \mathrm{nm}^{2}$ for MD6 and 0.12 proteins $/ \mathrm{nm}^{2}$ for MD9. 


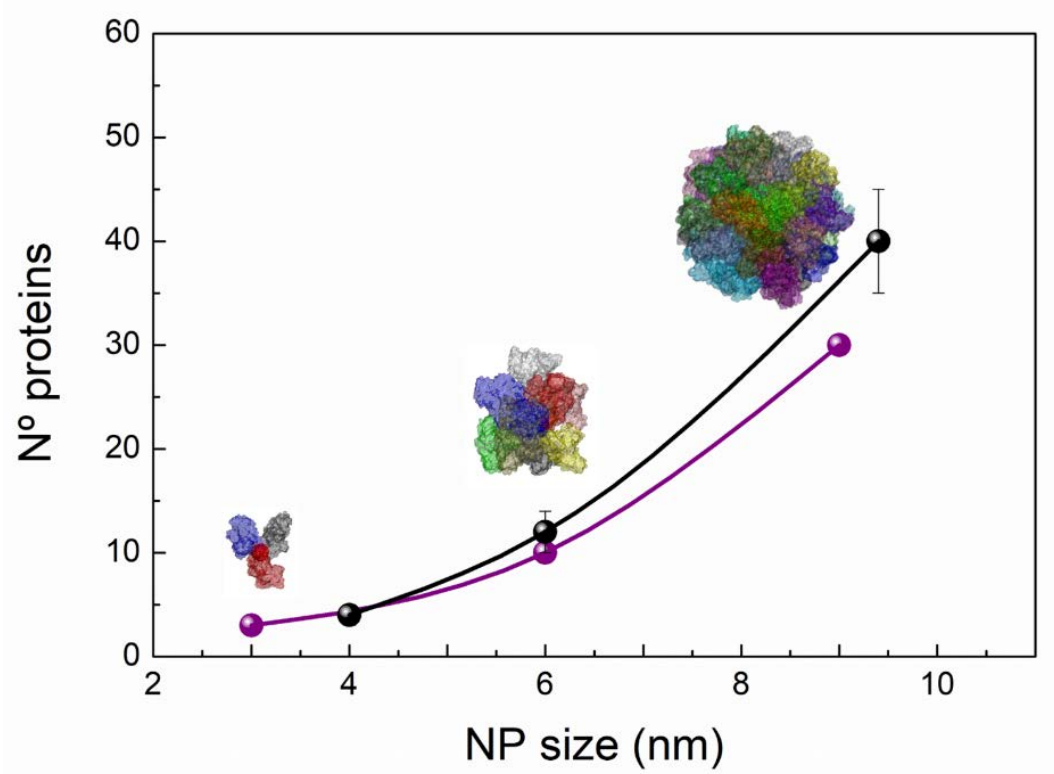

Figure 3. Number of proteins as a function of the diameter of the citrated-coated SPIONs Comparison between MD simulation results (violet dots) and experimental ones from fluorescence measurements (black dots). Solid lines serve as guide to the eye. Each experimental point is an average of three independent batches, error bars are the standard deviations of the three replicates.

Then, we studied the structure of the protein corona in each case by computing the radial density profile of protein backbone atoms across the protein corona (Figure 4). Snapshots of the simulations are also provided in order to help interpretation of the density profiles. In the three cases, the density profile has an adsorption peak at contact with the surface, a region with an approximately constant density of atoms (compact protein layer) and a decay of the density profile (diffuse profile). In the case of the particles with 3 and $6 \mathrm{~nm}$ of diameter (MD3 and MD6), the size of the region of compact protein layer is $3.2 \mathrm{~nm}$ and $3.5 \mathrm{~nm}$ respectively. This size of the compact region of the protein corona as determined by MD simulations is in agreement with the experimental results discussed above and obtained from different experimental techniques (DLS and TEM). Results shown in Figure 4, also portray that in both cases, there is a diffuse region with a low density of protein backbone atoms which extends up to a distance of $\approx 3 \mathrm{~nm}$ from the compact protein layer.

For the larger NP (9 nm, MD9), the region of compact layer has a $6 \mathrm{~nm}$ thickness, much larger than the diffuse region which in this case has only $\approx 1.5 \mathrm{~nm}$. This indicates that MD9 has a more compact protein corona than the smaller particles. The snapshots of the simulations shown in Figure 4 illustrate this effect. The simulations indicate that for the largest particle, the adsorbed proteins are in close contact not only near the NP surface but also in mutual contact along almost all the protein. However, in the case of simulation MD9, results should be interpreted with caution, in spite of the agreement with experiments in the number of adsorbed proteins. We should keep in mind that the large number of proteins and the extremely large number of atoms involved in the simulations (in the very limit of feasibility of MD simulations) induce an extremely sluggish dynamics in the simulations preventing being completely sure of a full equilibration of the atomic configurations for MD9.

Summarizing, we can say that the high curvature of the smallest particles makes the proteinprotein contact difficult and that the protein corona of HSA-S9 as obtained in simulations is more compacted than the protein corona of the other two particles (HSA-S3 and HSA-S6) which is much more diffuse. 

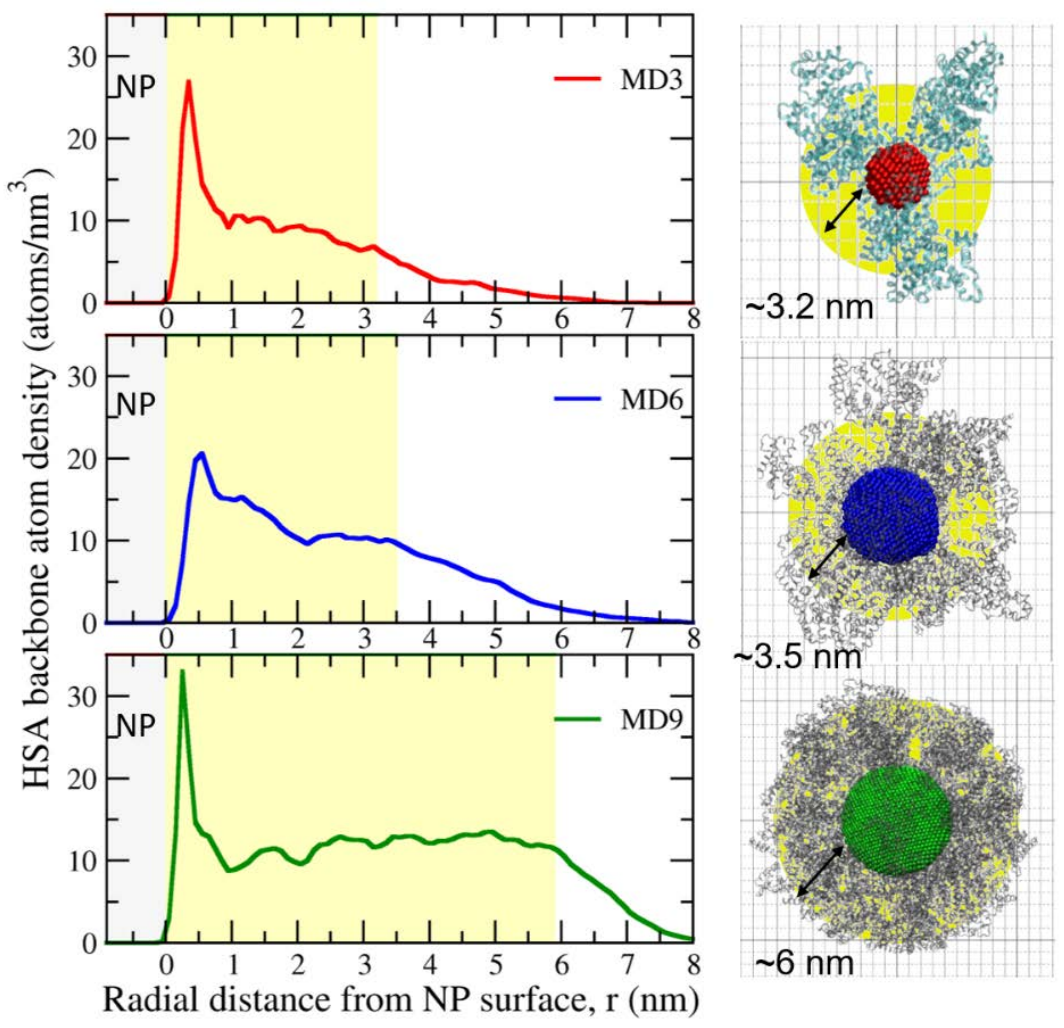

Figure 4. HSA backbone radial density profile for MD3, MD6 and MD9 calculated over the simulation production runs. The orange intervals show the zone where the protein forms a compact layer. Right panel displays snapshots of the protein corona for MD3, MD6 and MD9 simulations indicating the region of compact protein layer. The proteins are shown in ribbons representation. We include a grid in all snapshots with a grid length of $0.1 \mathrm{~nm}$ to facilitate interpretation. The size of the compact protein layer is also indicated in the snapshots.

We have also determined the fraction of atoms on the NP surface in contact with water solvent, and the fraction in direct contact with protein atoms. The results are shown in Figure 5. We obtained that the fraction of surface atoms in contact with water is smaller for the $3 \mathrm{~nm} \mathrm{NP}$ $(\approx 22 \%)$. This fact is due to the proteins distribution on the NP surface, which are more spread on the smaller NP (this can be also seen in the snapshot in Figure 4). Overall, the above results indicate that meaningful set of data can be extracted by combining MD simulations with experimental techniques. 
a)

MD3

MD6 MD9

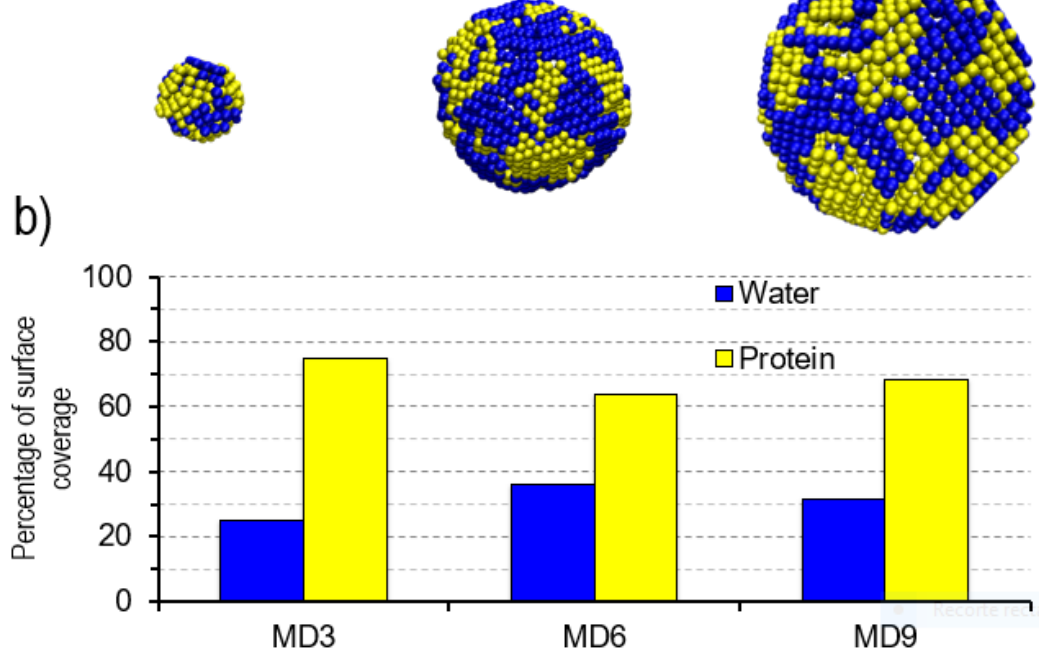

Figure 5. a) Snapshot of the NP in system MD3, MD6 and MD9 indicating in colors the surface atoms in contact with water (blue) and in contact with protein (yellow). b) Percentage of surface coverage of water (blue) and protein (yellow).

Next, we evaluated the strength of the interaction between HSA and the inorganic core. We use fluorescence spectroscopy by monitoring the tryptophan group (Trp 214) of the HSA which is highly sensitive to slight conformational changes of the HSA structure. Note that HSA contains two other fluorophores groups; tyrosine (Tyr) and phenylalanine (Phe), but with low quantum yield. ${ }^{34}$ Figure S6a shows the fluorescence spectrum for $4.5 \cdot 10^{-6} \mathrm{M}$ HSA excited at $295 \mathrm{~nm}$, which exhibit an emission band at $349 \mathrm{~nm}$. Upon addition of SPIONs and up to $68 \mu \mathrm{M}$, there is no shift in the emission band, which confirms that the secondary structure of HSA remains almost intact. ${ }^{35}$ Besides, in the same molar concentrations, we observe a decay of the fluorescence intensity (quenching effect) upon the addition of SPIONs regardless of their size. A Stern-Volmer equation (eq1) can be used to determine the influence of the quencher on proteins. ${ }^{36}$

$$
F_{0} / F=1+K_{q} \tau_{0}[S P I O N s] \quad \text { equation } 1
$$

where $F_{0}$ and $F$ are the fluorescence intensities of HSA in the absence and presence of SPIONs. $K_{q}$, the quenching constant $\left(\mathrm{M}^{-1} \mathrm{~s}^{-1}\right)$, usually described as $K_{q}=K_{s v} / \tau_{0}$, where $K_{s v}$ is the SternVolmer constant $\left(\mathrm{M}^{-1}\right)$ and the $\tau_{0}=5.8 \cdot 10^{-9} \mathrm{~s}$ is the characteristic lifetime of $\operatorname{Trp} 214 . \mathrm{K}_{\mathrm{q}}$ gives us information about the interaction strength of the system, where $\mathrm{K}_{\mathrm{q}}>2 \cdot 10^{12} \mathrm{M}^{-1} \mathrm{~s}^{-1}$ indicates a static mechanism while $\mathrm{K}_{\mathrm{q}}<2 \cdot 10^{12} \mathrm{M}^{-1} \mathrm{~s}^{-1}$ a dynamic one. ${ }^{36} \mathrm{~K}_{\mathrm{q}}$ values for our systems $\left(\sim 5 \cdot 10^{12}\right.$ $\mathrm{M}^{-1}$ ) reveal a static mechanism between SPIONs and HSA indistinctly of the particle size (see Figure S6 b,d), these values are slightly smaller to one obtained for BSA for S6 $\left(\mathrm{K}_{\mathrm{q}}=7 \pm 0.2 \cdot 10^{12}\right.$ $\left.\mathrm{M}^{-1} \mathrm{~s}^{-1}\right) .^{28}$

Moreover, we can get further inside on the interaction mechanism by evaluating the binding constant $\left(K_{a}\right)$ and the number of bindings sites $(n)$ using the equation 2 :

$$
\log F 0-\mathrm{FF}=\log \mathrm{Ka}+\mathrm{n} \log [\mathrm{SPIONs}] \quad \text { equation } 2
$$


In all cases $\mathrm{n} \approx 1$, indicating one binding site of HSA on SPIONs surface. $K_{a}$ is $\sim 10^{5} \mathrm{M}^{-1}$ revealing a strong interaction between SPIONs and the HSA (Figure S6c). Note that, using the same method, Czub et al. have very recently reported $K_{a} \sim 310^{3} \mathrm{M}^{-1}$-two orders of magnitude smaller- for testosterone-albumin conjugates. ${ }^{37}$ In general terms, our results are comparable to those obtained for BSA $\left(K_{a} \sim 510^{5} \mathrm{M}^{-1}\right)$ as expected from their very similar structures. ${ }^{38}$ Thus, we believe that the citrate groups on the particle surface mediate a strong electrostatic interaction and the formation of very robust HSA-SPIONs. ${ }^{28}$ Moreover, our results are in good agreement with previous works for iron oxide particlese. . $^{39,40}$

As mentioned, considering that SPIONs are extensively used as in vitro and in vivo as MRI contrast agents, the impact of a preformed protein coating on the MRI relaxivity values ( $r_{1}$ and $\mathrm{r}_{2}$ ) was evaluated in water, human plasma and PBS. In the case of PBS, relaxivities after short and long-term storage time of the dispersions were assessed. Figures 6a-b shows the expected linear relationship of $1 / T_{2}$ versus iron concentrations for the citrate-coated SPIONs (S-series) and the HSA-SPIONs (HSA-series). $\mathrm{r}_{2}$ values are gathered in the table included in Figure 6e. The S9 and HSA-S9 systems are the most efficient ones in diminishing $T_{2}$ as one would expected from their largest volume and $\mathrm{M}_{\mathrm{s}}$ (largest magnetic moment). Importantly, the preformed protein corona does not affect the efficiency of the SPIONs as transverse contrast agents. Figures $6 \mathrm{c}$ and 6d show $1 / T_{2}$ for particles being incubated in human plasma for 3 days. Relaxivity values slightly increase for all systems, more evident in the S9 and HSA-S9 systems, but without noticeable differences between the S-series and the protein nanoconjugates, the HSA-series. This points out to the fact that the proteins present in plasma have formed a protein corona similar to the preformed one for the citrate-coated nanoparticles but did not aggregate them further; also, no meaningful aggregation was detected for the HSA-series. Our results are in good agreement with other works investigating the impact of an acquired protein corona on the relaxivities values. ${ }^{18,19}$ 

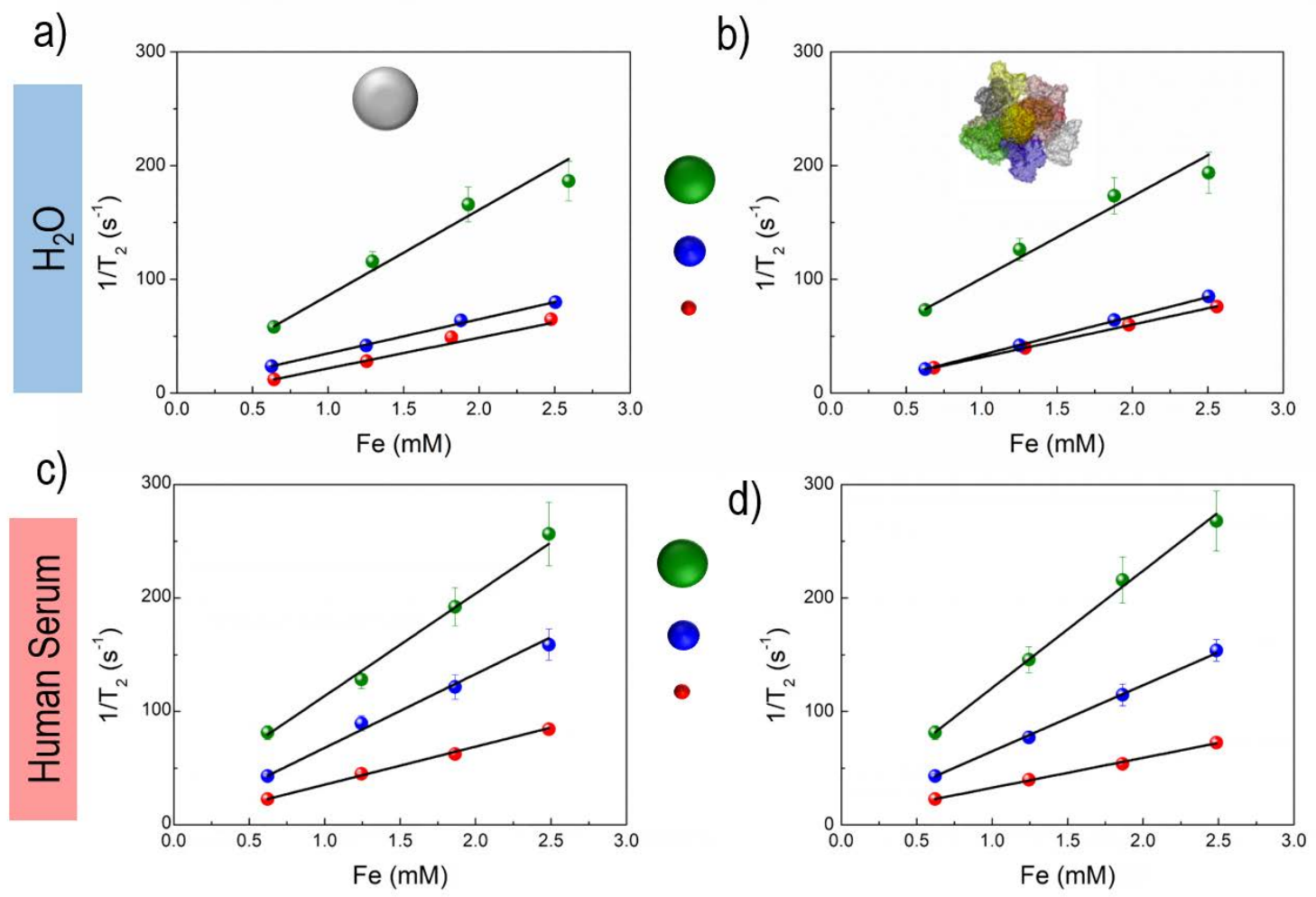

e)

\begin{tabular}{|c|c|c|c|c|c|c|c|}
\hline \multicolumn{4}{|c|}{$\mathrm{H}_{2} \mathrm{O}$} & \multicolumn{4}{|c|}{ Human Serum } \\
\hline SPIONs & $\begin{array}{c}\mathrm{r}_{2} \\
\left(\mathrm{~s}^{-1} \mathrm{~m}^{-1} \mathrm{M}^{-1}\right)\end{array}$ & $\begin{array}{l}\text { HSA- } \\
\text { SPION's }\end{array}$ & $\begin{array}{c}r_{2} \\
\left(s^{-1} \mathrm{mM}^{-1}\right)\end{array}$ & SPIONs & $\left(s^{-1} \mathrm{~mm}^{r_{2}}\right)$ & $\begin{array}{l}\text { HSA- } \\
\text { SPIONs }\end{array}$ & $\begin{array}{c}\mathrm{r}_{2} \\
\left(\mathrm{~s}^{-1} \mathrm{~m}^{-1}\right.\end{array}$ \\
\hline s4 & $27 \pm 1$ & HSA-S4 & $29 \pm 1$ & S4 & $33 \pm 1$ & HSA-S4 & $26 \pm 1$ \\
\hline s6 & $30 \pm 1$ & HSA-S6 & $30 \pm 1$ & s6 & $65 \pm 1$ & HSA-S6 & $58 \pm 1$ \\
\hline s9 & $75 \pm 7$ & HSA-S9 & $72 \pm 7$ & s9 & $90 \pm 7$ & HSA-S9 & $103 \pm 5$ \\
\hline
\end{tabular}

Figure 6. Plot of $\mathrm{T}_{2}{ }^{-1}$ versus Fe concentration for $\mathrm{S}$ (left) and $\mathrm{H}$-series of samples (right) after being incubated 3 days in water a-b) and in human serum c-d). e) Summary table with $r_{2}$ values for all samples.

The results for longitudinal relaxation times $\left(\mathrm{T}_{1}\right)$ are included in Fig S7. Since for positive agents the most important spin-lattice relaxation mechanism is that of an inner sphere in which protons have to be in contact with the relaxation agent, we observe a huge difference between the $\mathrm{r}_{1}$ values for the S-series and the HSA-series. Of particular interest here is the comparison between S4 and HSA-S4.

In addition, we monitored by DLS and MRI our samples up to 90 days after being incubated in PBS (see Figure 7 and S8, in SI). After 3 days, there are no significant changes on the hydrodynamic diameter, $\mathrm{D}_{\mathrm{h}}$, for both series. This is confirmed by the relaxivity values gathered in Figure 6c, showing similar values to those obtained in $\mathrm{H}_{2} \mathrm{O}$, except for the slightly larger values of S9. It takes between 15 to 21 days to the S-series to start to destabilize, showing a noticeable increase in $\mathrm{D}_{\mathrm{h}}$ values, typical of big agglomerates. After 3 months, all the particles from the Sseries have precipitated and not even strong shaking could enable measuring the relaxation times. This scenario is very different for the protein preformed series where the relaxivity values remain constant even after three months, thus, evidencing the lack of aggregation in PBS of the HSAseries (Figure 7). 
The apparent difference found in S- and HSA- series can be explained owing to the combination of electrostatic and steric interactions of the particle coating. Both, citrate and HSA have a comparable negative $\zeta$-potential but HSA occupies a larger volume. In a medium with low concentration of salts as for example water, there is a low ionic strength that allows a large ion cloud in the particle surface and inhibits the particle interaction regardless its coating. ${ }^{41}$ However, in PBS, a media with high concentration of salts, the high ionic strength compresses the ionic double layer inducing particle agglomeration. However, greater molecules as proteins have shown to enhance the stability via steric interactions. ${ }^{28,41}$
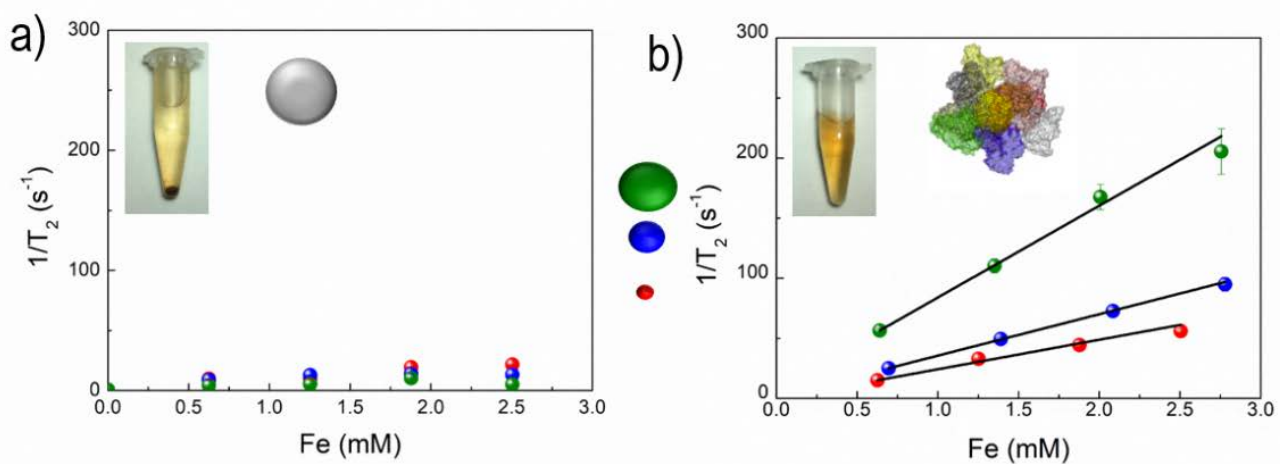

C) \begin{tabular}{|c|c|c||c|c|}
\hline SPIONs & $\begin{array}{c}\mathrm{r}_{2} \text { in PBS, } 3 \text { days } \\
\left(\mathbf{s}^{-1} \mathrm{mM}^{-1}\right)\end{array}$ & $\begin{array}{c}\text { HSA- } \\
\text { SPIONs }\end{array}$ & $\begin{array}{c}\mathrm{r}_{2} \text { in PBS, } 3 \text { days } \\
\left(\mathbf{s}^{-1} \mathrm{mM}^{-1}\right)\end{array}$ & $\begin{array}{c}\mathrm{r}_{2} \text { in PBS, } 90 \text { days } \\
\left(\mathbf{s}^{-1} \mathrm{mM}^{-1}\right)\end{array}$ \\
\hline S4 & $23 \pm 1$ & HSA-S4 & $24 \pm 2$ & $24 \pm 2$ \\
\hline S6 & $36 \pm 1$ & HSA-S6 & $33 \pm 2$ & $34 \pm 2$ \\
\hline S9 & $93 \pm 5$ & HSA-S9 & $74 \pm 5$ & $76 \pm 3$ \\
\hline
\end{tabular}

Figure 7. $\mathrm{T}_{2}{ }^{-1}$ versus Fe concentration for the a) SPIONs-series and b) HSA-series after an incubation period of 90 days in PBS. c) Relaxivities $r_{2}$ for SPIONs-series for 3 days (left) and HSA-series for 3 and 90 days in PBS.

To recapitulate, the preformed corona does not decrease $T_{2}$ relaxation efficiency in water or human plasma, but it has a huge beneficial effect when considering particles kept for long periods in other media, such as PBS. On the other side, the preformed corona is detrimental when smaller size SPIONs are intended as $T_{1}$ agents since the protein is hindering the intimate contact of the water protons with the particle surface. Even though, as seen by MD simulations in Figure 4, there is a $22 \%$ of the nanoparticle surface accessible to the water protons. The low $r_{1}$ values that have been obtained in presence of an acquired or a preformed corona are somehow in contradiction with the good in vivo relaxivity performance of very small iron oxide nanoparticles, as shown for instance in reference and deserve further analysis. ${ }^{3}$

Next, we have studied the iron oxide dissolution kinetics in acid media $(0.2 \mathrm{M} \mathrm{HCl})$ to investigate the nanoparticle survival in acidic biological environments such as the gastric media. Note that the $\mathrm{pH}$ in human gastric ranges from 1.5 to $3 .{ }^{42}$ Experiments were performed for $\mathrm{S}$ - and HSA- samples using concentrations of $0.35 \mathrm{mM}$ Fe and monitoring the iron oxide dissolution kinetics by UV-vis and the sample stability by DLS for seven days (Figures 8, S9 and S10). Figure 8a shows three characteristic absorbance spectra for the iron oxide dissolution in $\mathrm{HCl}$ media for S6. Blue absorbance spectrum for S6 without the presence of acid reveals the typical features of $\mathrm{Fe}_{2} \mathrm{O}_{3} / \mathrm{Fe}_{3} \mathrm{O}_{4}{ }^{43}$ Absorbance steadily increases from 600 to $200 \mathrm{~nm}$ and no distinctive absorption 
band appears. The same sample under $0.2 \mathrm{M} \mathrm{HCl}$ for $5 \mathrm{~h}$ exhibits a decrease of absorbance in the range of 400 to $600 \mathrm{~nm}$ and a plateau from 300 to $400 \mathrm{~nm}$ (purple spectrum). At the end of the reaction, the absorbance signature is very different. There is a band around $340 \mathrm{~nm}$ and the absorbance tends to zero from 400 to $800 \mathrm{~nm}$ (black spectrum). These different features have allowed estimating the iron oxide dissolution kinetics into iron chloride species. Figures 8b, 8c and $8 \mathrm{~d}$ present the iron oxide dissolution into $\mathrm{Fe}^{3+}$ ions as a function of time for the S-series (empty dots) and the HSA-series (full dots). The first observation is a fast dissolution speed of the citrate-coated SPIONs. For instance, after $10 \mathrm{~h}$ full dissolution has occurred for the S4 particles while still $40 \%$ of iron in the form of iron oxide remains in the HSA-S4 nanoconjugate. Similar observations, at longer times, can be seen for the larger sizes.

We gained insight about the efficiency of the protective effect of HSA over the particle surface by comparing the ratio $\left(\mathrm{A}_{\mathrm{HSA}-} / \mathrm{A}_{\mathrm{S}-}\right)$ at half-reaction times $\left(\mathrm{A} / \mathrm{A}_{0}=0.5\right)$. The ratio $\left(\mathrm{A}_{\mathrm{S} 4-\mathrm{HSA}}\right.$ $\left./ \mathrm{A}_{\mathrm{s4-}}=8\right)$ is larger than for $\left(\mathrm{A}_{\mathrm{S6}-\mathrm{HSA}-} / \mathrm{A}_{\mathrm{S6}-}=4\right.$ and $\left.\mathrm{A}_{\text {s9-HSA-}} / \mathrm{A}_{\mathrm{sg-}}=3\right)$. We believe that this is resulting from the fact that HSA are more spread in the particles and consequently protecting more effectively the particles from digestion (see the HSA configuration for each size in the snapshots of Figure 4). These results are in good agreement with the greater number of atoms in contact with the protein found for smaller particles ( $\approx 78 \%$ for MD3).

We have thus shown that our well-controlled preformed protein corona protects the integrity of the SPIONs. This fact may be advantageous when MRI scans have to be repeated periodically without the re-administration of the contrast agent. We have also plotted the time evolution of the hydrodynamic diameter, $\mathrm{D}_{\mathrm{h}}$, of the HSA-series (insets of Figures 8b-d). A very interesting fact, easier to observe for HSA-S9 is that at i.e. $25 \mathrm{~h}, 40 \%$ of the initial iron in the form of maghemite has converted to $\mathrm{Fe}^{3+}$ without noticeable variation in the nanoconjugate hydrodynamic size. This observation suggests that the protein corona remains intact albeit a fraction of the iron has dissolved into the media in accordance to the MD results that indicates strong protein-protein interaction for the HSA-S9 system. In consequence, free space inside the protein corona is left. Interestingly, preliminary MD included as a video and in Figure S11 show that for HSA-S6 it would be possible to fully dissolve the inorganic core and form a stable albumin cage. Here we advocate that controlled dissolution of a fraction of the iron oxide core opens the opportunities for theranostic for these HSA-iron oxide nanocages. 

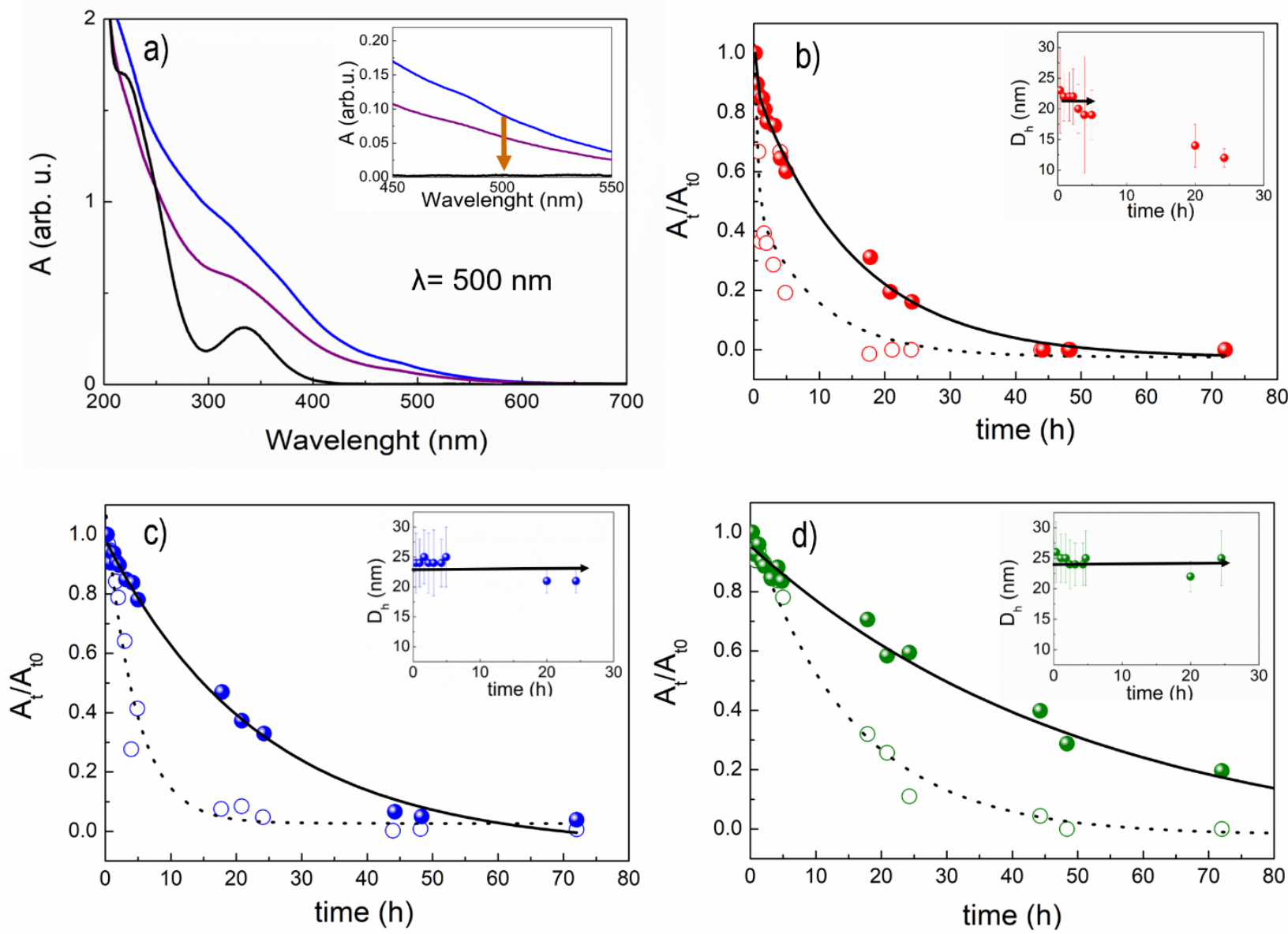

Figure 8. The effect of the HSA corona on the SPIONs stability in $\mathrm{HCl} 0.2 \mathrm{M}$. a) UV-vis spectra for S6 (blue line) in $0.2 \mathrm{M} \mathrm{HCl}$ at $\mathrm{t}=0$ and after $5 \mathrm{~h}$ (purple line) and $48 \mathrm{~h}$ (black line). Inset shows a blown up for wavelengths between 450 and $550 \mathrm{~nm}$. Evolution of absorbance as a function of time at $500 \mathrm{~nm}$ for SPIONsseries (empty dots) and HSA-series (solid dots). b) S4 (red), c) S6 (blue) and d) S9 (green). Upper insets reveal $\mathrm{D}_{\mathrm{h}}$ evolution along $24 \mathrm{~h}$ after the addition of $\mathrm{HCl}$.

\section{Conclusions}

Guided by molecular dynamic simulation we have established a protocol to easily synthesize human serum albumin-iron oxide nanoconjugates of different sizes with a reproducible number of proteins in the corona. The simulations indicate the presence of a compact protein corona with a size compatible with DLS and TEM measurements. We demonstrated that the citrate groups on the surface of the iron oxide particles mediate strong electrostatic interactions between the protein and the inorganic core and the formation of very robust HSA-SPIONs nanoconjugates. We have thus presented a universal route to preform a strongly attached and a well-defined monolayer of human albumin onto iron oxide nanoparticles. Note that citrate is commonly employed to functionalize all types of inorganic nanoparticles and in this sense, the results obtained can be considered to go beyond the iron oxide system. The impact on the efficiency of the HSA-SPIONs as $T_{1}$ and $T_{2}$ contrast agents was investigated. We could establish that the albumin preformed corona has a detrimental effect for ultrasmall SPIONs acting as $\mathrm{T}_{1}$ contrast but a beneficial one for larger particles acting as $T_{2}$ since it increases considerably the shelf-life of the formulations, for instance, when stored in PBS. Finally, we accurately determined the dissolution kinetics, in acidic media, of protein protected and the unprotected inorganic cores. We concluded on the bio- 
shielding effect of the albumin against rapid dissolution of the iron oxide core. Further, we argue that with the partial dissolution of the inorganic core we could paved the way towards theranostic HSA-SPIONs nanoconjugates by liberating space inside the protein cage that could be subsequently loaded with therapeutic agents.

\section{Experimental and Computational Methods}

Materials. Iron (III) acetylacetonate $\left(\mathrm{Fe}(\mathrm{acac})_{3} \geq 97 \%\right)$, trisodium citrate dehydrate ( $\mathrm{Na}_{3} \mathrm{Cit} \cdot 2 \mathrm{H}_{2} \mathrm{O} \geq 99 \%$ ), Phosphate-buffered saline (PBS, 10010-023-0.5l), Human Serum (H4522-20 ml), Human Serum Albumin (HSA, A1887-1G) and Hydrocloridric acid (HCl, 37\%) were purchased from Sigma-Aldrich. Benzyl-alcohol (BA, 99\%) and nitric acid $\left(\mathrm{HNO}_{3}\right.$, $65 \%$ ) were bought from Sharlab and Panreac, respectively. Milli-Q water (MQ- $\left.\mathrm{H}_{2} \mathrm{O}\right)$ was used. All materials were used as-received without further purification.

Synthesis of citrate-coated SPIONS. $6 \mathrm{~nm}$ citrate-coated iron oxide nanoparticles (SPIONs) (S6) were prepared by microwave (MW)-assisted thermal decomposition synthesis in a CEM Discover reactor (Explorer 12-Hybrid) at a frequency of $2.45 \mathrm{GHz}$ and $300 \mathrm{~W} .{ }^{44} \mathrm{NP}$ size was tuned with slight modifications of the protocol described in ${ }^{28}$

$4 \mathrm{~nm}$ SPIONs (S4) were fabricated by mixing $0,123 \mathrm{~g}$ of $\mathrm{Fe}(\mathrm{acac})_{3}$ ( $3.5 \mathrm{mmols}$ ) in $4.5 \mathrm{ml}$ of BA for one minute. Thereafter, the reaction mixture was heated first to $60^{\circ} \mathrm{C}$ for $5 \mathrm{~min}$ to ensure a complete dispersion of the precursor, and then at $180^{\circ} \mathrm{C}$ for $4 \mathrm{~min}$. The reaction was then cooled down at $50^{\circ} \mathrm{C}$ in 3 min using compressed air and transferred to a centrifugation tube together with $35 \mathrm{ml}$ of acetone. After centrifugation three times at $6000 \mathrm{rpm}$ for $20 \mathrm{~min}$, a black powder was dried at room temperature for $1 \mathrm{~h}$. Then, $3 \mathrm{ml}$ of $\mathrm{Na}_{3} \mathrm{Cit} \cdot 2 \mathrm{H}_{2} \mathrm{O}$ at $3 \%(\mathrm{w} / \mathrm{w})$ were added and the mixture was left overnight under mechanical stirring. Then, the sample was precipitated by centrifugation at same conditions than above and the precipitated was dried at $60{ }^{\circ} \mathrm{C}$ for $8 \mathrm{~h}$. Finally, the powder was dispersed in $3 \mathrm{ml}$ of $\mathrm{MQ}-\mathrm{H}_{2} \mathrm{O}$.

$9 \mathrm{~nm}$ SPIONs (S9) were synthesized by increasing up to $1.23 \mathrm{~g}$ the amount of $\mathrm{Fe}(\mathrm{acac})_{3}$ (3.5 mmols) and the reaction temperature $\left(210^{\circ} \mathrm{C}\right)$ for $60 \mathrm{~min}$. After the reaction, the solution was cooled down to room temperature and NPs were collected by centrifugation two times with acetone at $6000 \mathrm{rpm}$ for $20 \mathrm{~min}$ and left dried $1 \mathrm{~h}$ at room temperature. S9 was stabilized in aqueous media with the same protocol than before but using $10 \mathrm{ml} \mathrm{Na}{ }_{3} \mathrm{Cit} \cdot 2 \mathrm{H}_{2} \mathrm{O}$ at $3 \%(\mathrm{w} / \mathrm{w})$. All samples were filtered using a Millex VV filter with a $0.1 \mu \mathrm{m}$ of porous of size in order to purify the samples.

Albumin corona on SPIONs (HSA-SPIONs). We extended our previous methodology for the coating of different SPIONs size. Briefly, the $\mathrm{pH}$ of $1 \mathrm{ml}$ of citrate-coated SPIONs with (3.13 $\mu \mathrm{M} \mathrm{Fe}_{2} \mathrm{O}_{3}$ ) was adjusted to $\mathrm{pH}=11$ using $\mathrm{NaOH}, 0.1 \mathrm{M}$. Then, the solution was mixed with $1 \mathrm{ml}$ of HSA ( $35 \mu \mathrm{M}$ of HSA) and left $1 \mathrm{~h}$ under mechanical stirring. Afterwards, the $\mathrm{pH}$ was adjusted to 7.4 with $\mathrm{HNO}_{3} 0.1 \mathrm{M}$. To remove the excess of HSA, $2 \mathrm{ml}$ of HSA-SPIONs were purified by centrifuging at $2264 \mathrm{~g}$ for $15 \mathrm{~min}$ using centrifugal filter units (Amilcon, $1000000 \mathrm{MW}$ Millipore). After each washed, the supernatant was collected, weighted and three fluorescence spectra were recorded. Concentrated HSA-SPIONs were then redispersed in $2 \mathrm{ml}$ of $\mathrm{MQH}_{2} \mathrm{O}$ and centrifuged again under the same conditions. This protocol was repeated for each sample in triplicate until the supernatant did not show a peak around $349 \mathrm{~nm}$ (Fig S5 in SI). The amount of HSA in each supernatant was calculated with a calibration curved formed by the average of five standards of HSA with concentrations ranging from 0.05 to $1 \mathrm{mg} / \mathrm{ml}$. (Fig S5). The amount of HSA forming the protein corona was calculated by subtracting the HSA free to the initial amount of HSA. Moreover, the number of NPs for each sample was calculated assuming spherical $\gamma$ $\mathrm{Fe}_{2} \mathrm{O}_{3}$ NPs with a density of $\rho=4.90 \mathrm{~g} \cdot \mathrm{cm}^{-3}$ by the following expression: 
$N$ oparticles $=g \mathrm{Fe}_{2} \mathrm{O}_{3} \cdot \frac{1}{\rho} \cdot \frac{1}{V}$ equation 3

where $V\left(\mathrm{~cm}^{3}\right)$ is the Volume for a NP using the average particle size from TEM measurements. Finally, by dividing the number of HSA for each NP size was determined the number of HSA for each NP size. HSA-S4 (4 \pm 1 HSA), HSA-S6 (12 \pm 1 HSA) and HSA-S9 (40 \pm 5 HSA).

\section{Characterization}

Transmission electron microscopy (TEM). Samples were prepared by addition of one drop onto a carbon film copper grid. The excess was blotted with a filter paper and letting it dry at room temperature. SPIONs were analyzed by using a JEOL JEM-1210 operating at $120 \mathrm{kV}$. Size distributions were obtained by measuring at least $250 \mathrm{NPs}$ and the resultant histograms were fitted to Gaussian functions. NPs crystallographic phase was identified by selected area electron diffraction (SAED). Atomic resolution Z-contrast (or high angle annular dark field, HAADF) images in STEM mode were performed in a FEI Titan 60-300 kV equipped with a probe corrector and operated to $80 \mathrm{kV}$.

Negative-staining TEM to image the HSA corona. $8 \mu \mathrm{L}$ of concentrated HSA-SPIONs were placed on a TEM grid and full evaporated at room temperature. Then, the TEM grid was submerged in benzoate for $5 \mathrm{~min}$, washed with $\mathrm{MQ}-\mathrm{H}_{2} \mathrm{O}$ and dried it with a filter paper. This procedure was repeated three times to ensure the full fixation of the HSA. After that, TEM grid was submerged in glutaraldehid $2.5 \%$ for 5 min. $8 \mu$ of uranyl acetate $2 \%$ was placed on the grid for $1 \mathrm{~min}$ before draining it off. HSA corona was visualized using the same conditions described previously.

Dynamic light scattering (DLS). Hydrodynamic diameter $\left(\mathrm{D}_{\mathrm{h}}\right)$ of samples was determined using a Zetasizer Nano ZD (Malvern) equipment with a He/Ne $633 \mathrm{~nm}$ laser at $298 \mathrm{~K}$. Results for each sample were obtained from the average of 3 measurements with 11 scans for each measurement.

$\zeta$-potential. Sample solutions were measured in a Zetasizer Nano ZS (Malvern). For each measurement, 10 cycles were collected and three independent measures were performed.

Fluorescence measurements. Samples were recorded on a fluorescence spectrophotometer (HITACHI F-7000, Japan) at $298 \mathrm{~K}$, in a rectangular quartz cell with a path of $10 \mathrm{~mm}$. Emission spectra were recorded by exciting at $295 \mathrm{~nm}$ using 10 per $10 \mathrm{~nm}$ (excitation/emission) slit widths. The fluorescence emission spectra were collected from 250 to $500 \mathrm{~nm}$. Each spectrum is the result of the average of three scans.

UV-visible spectroscopy (UV-vis). UV-Vis spectra were collected on a Varian Cary-5 UVVis spectrophotometer ranging from 200 to $800 \mathrm{~nm}$ using high precision cuvettes made of quartz with a Light path of $10 \mathrm{~mm}$. Each UV-vis spectrum was the average of three scans.

Inductively coupled plasma optical emission spectroscopy (ICP-OES). Fe composition for the samples was determined with an ICP-OES Perkin-Elmer Optima 4300DV which worked in an Fe range from 15 to $35 \mathrm{mg} / \mathrm{l} .0 .1 \mathrm{ml}$ of concentrated SPIONs were digested in $1 \mathrm{ml}$ of $\mathrm{HNO}_{3}$ (65\%) under sonication for $30 \mathrm{~min}$. After that, the mixture was diluted in a $50 \mathrm{ml}$ volumetric flask with MQ- $\mathrm{H}_{2} \mathrm{O}$.

Superconducting quantum interference device (SQUID). Magnetization measurements of $50 \mu \mathrm{L}$ of SPIONs of $1 \mathrm{mg} / \mathrm{ml}$ were performance with a Quantum Design MPMS5XL magnetometer. Hysteresis loops were recorded at $300 \mathrm{~K}$ under a maximum field of $\pm 70 \mathrm{kOe}$. Saturation magnetization $\left(\mathrm{M}_{\mathrm{s}}\right)$ values were normalized to the magnetic mass determined by ICP. Zero field cooled (ZFC) magnetization curves were measured from 5-300 K with a magnetic field of 50 Oe. 
Magnetic resonance imaging (MRI). Longitudinal $T_{1}$ and transverse $T_{2}$ relaxation times were measured using a BioSpec 70/30 USR superconducting magnet of both SPIONS and HSASPIONs dispersions with concentrations ranging from 0.5 to $2.5 \mathrm{Fe} \mathrm{mM}$ in $\mathrm{MQ}-\mathrm{H}_{2} \mathrm{O}, \mathrm{PBS}$ and in Human Serum (HS). Samples were previously incubated in the corresponding medium at constant shaking in a rotor at room temperature. Longitudinal $r_{1}$ and transverse $r_{2}$ relaxivities were calculated from the slope of the linear fitting of $\mathrm{T}_{1}^{-1}$ and $\mathrm{T}_{2}{ }^{-1} v s[\mathrm{Fe}]$.

Study of the sample degradation in acid media. Solutions with $0.2 \mathrm{M}$ of $\mathrm{HCl}$ and iron concentration of $20 \mathrm{mg} / \mathrm{l}$ were prepared for S- and HSA- series before following this protocol: first, diluted solutions were prepared from their corresponding mother solutions. Then, $66 \mu \mathrm{L}$ of 12.17 $\mathrm{M}$ of $\mathrm{HCl}$ were added and samples were vortexed per $1 \mathrm{~min}$. The reaction stages were monitored by UV-vis spectroscopy at room temperature during during 7 days. The reaction yield was obtained as the quotient of absorbance between the sample at given time and the initial amount at $\lambda=500 \mathrm{~nm}$. During the reaction, DLS measurements were also performed to study the sample stability.

Molecular Dynamics (MD) simulations. We performed MD all-atomic simulations of the protein corona (made by HSA protein) of three nanoparticles of different number of atoms. We considered a NP with 546 atoms (MD3 $\approx 3 \mathrm{~nm}$ of diameter), a NP with 4104 atoms (MD6 $\approx 6 \mathrm{~nm}$ ) and 12219 atoms $(\mathrm{MD} 9 \approx 9 \mathrm{~nm})$. Protein structures with full atomistic detail were obtained from Protein Data Bank (code PDB:1e78), adding the missing hydrogens with the VMD program ${ }^{45}$. In all our simulations we described the protein interactions with the CHARMM36 force field. The interactions between NP atoms and the protein were described with an effective potential as in our previous work. ${ }^{28}$ Due to the large number of atoms in our simulations, we have employed an implicit solvent model (the GBIS model) as in our previous work ${ }^{28}$. A review of the method can be found in ref. ${ }^{26}$ All MD simulations were performed by using the NAMD 2.12 software. ${ }^{46}$ In these simulations the Newton equations of motion were solved numerically with a time-step of 2 fs. The temperature was kept constant at $298 \mathrm{~K}$ using the Langevin thermostat with a relaxation constant of $1 \mathrm{ps}^{-1}$. All parameters for the GBIS model in NAMD were the same as employed in ref. ${ }^{47}$ The protocol of the simulations was as follows. In the case of simulations with the NP of diameter $3 \mathrm{~nm}$ (simulation MD3) and $6 \mathrm{~nm}$ (simulation MD6), we sequentially placed proteins in the system until no further proteins are adsorbed over the NP. We obtained 3 and 10 proteins respectively, so the simulated systems contain 27909 and 95314 atoms, respectively. The systems MD3 and MD6 were further simulated for 12,000,000 steps (note that due to the use of implicit solvent, the kinetics of the simulation cannot be easily related to real, physical time. ${ }^{26}$ In the case of the NP with $9 \mathrm{~nm}$ of diameter (simulation MD9), this method proved to be computationally very expensive, so we employed an alternative approach. We generated an initial configuration of pre-adsorbed proteins using the program packmol. ${ }^{48}$ The maximum number of proteins that the program was able to allocate was 32 . Then, we performed a short simulation run to determine the stability of the adsorbed proteins. Two of the initially adsorbed proteins desorbed after $\sim 3,000,000$ simulation steps and 30 remained adsorbed. The simulation, with the NP and the remaining 30 proteins (with a total number of atoms of 285,849) was further continued for $~ 1,400,000$ steps. The results were analyzed with the VMD program and density profiles in the radial direction were obtained by using our own home-made code. The contacts between NP atoms and water were analyzed in the following way: we added explicit TIP3P water molecules to the final state of each of the previous implicit solvent simulations (MD3, MD6 and MD9) using the solvate algorithm as implemented in ${ }^{45}$. The resulting systems with added water contain 428,310 atoms for the MD3 case, 1,071,853 atoms for the MD6 case and 1,880,142 atoms for the MD9 case. In this case our objective was to determine which regions of the NPs were in contact with water in spite of the presence of the protein corona, so in principle the solvate algorithm of VMD provides a good first 
approximation since it adds water molecules in the available space. We further refine this estimation by performing short equilibration runs which allow water molecules to rearrange near the interfaces. Due to the associated computational cost of such large systems we only performed an equilibration run (100 ps). From the equilibrated final configuration, we calculated the number of surface atoms of NP as the atoms that are in contact either with water or protein at a distance of $0.35 \mathrm{~nm}$. We also calculated the percentage of surface coverage by water as the ratio between the surface atoms in contact with only water at $0.35 \mathrm{~nm}$ and the total number of atoms on the surface. The protein surface coverage was obtained from the remaining surface atoms necessary to obtain $100 \%$ coverage.

\section{Acknowledgments}

This work was partially supported by Grifols SA (2017 Albus Award to A.R). The Spanish Ministry of Science, Innovation and Universities through the MAT2015-64442-R and the 'Severo Ochoa' Programme for Centers of Excellence in R\&D (SEV-2015-0496) grants and the Generalitat de Catalunya (2017SGR765 grant) are also acknowledged. D. C. M. is supported by the EC H2020 Marie Sklodowska-Curie grant agreement No. 6655919. We thank CESGA Supercomputing center for technical support and computer time at the supercomputer Finisterrae II. We thank the colleagues, Dr S.Yu and Dr A. Laromaine, for earlier discussions and previous publications on the subject.

Supporting Information (SI) available: Characterization for samples S4, S6 and S9. Particle size distribution, Hysteresis loops at $300 \mathrm{~K}$, ZFC-FC curves, Zeta and Volume averaged hydrodynamic sizes at 0, 7.5 and 76.5 M HSA. Fluorescence spectra of the supernatants after centrifugation. Negative staining TEM images for HSA-S6. Fluorescence spectroscopy study for HSA-SPIONs. Relaxivities ( $\mathrm{r}_{1}$ ) for (S-) and (HSA-) series in $\mathrm{H}_{2} \mathrm{O}$, Human Serum and PBS. Volume averaged hydrodynamic size histograms for samples after 21 days. Representative volume averaged hydrodynamic size histograms for HSA-series under $0.2 \mathrm{HCl}$ for $24 \mathrm{~h}$. UV-vis for (S-) and (HSA-) series of samples for $0.36 \mathrm{mM}$ of Fe under $0.2 \mathrm{M}$ of $\mathrm{HCl}$. Molecular dynamics simulation of a HSA nanocage. 


\section{References}

(1) Ling, D.;Lee, N.;Hyeon, T. Chemical Synthesis and Assembly of Uniformly Sized Iron Oxide Nanoparticles for Medical Applications. Acc. Chem. Res. 2015, 48, 1276-1285.

(2) Taboada, E.; Rodríguez, E; Roig, A.; Oró, J.; Muller R. N. Relaxometric and Magnetic Characterization of Ultrasmall Iron Oxide Nanoparticles with High Magnetization. Evaluation as Potential T1 Magnetic Resonance Imaging Contrast Agents for Molecular Imaging. Langmuir 2007, 23, 4583-4588.

(3) Wei H. and et al. Exceedingly small iron oxide nanoparticles as positive MRI contrast agents. Proceedings of the National Academy of Sciences 2017, (9) 114, 2325-2330.

(4) Taboada, E.; Solanas, R.; Rodriguez, E.; Weissleder, R.; Roig, A. Supercritical-FluidAssisted One-Pot Synthesis of Biocompatible Core(gamma- $\left.\mathrm{Fe}_{2} \mathrm{O}_{3}\right) / \mathrm{Shell}\left(\mathrm{SiO}_{2}\right)$ Nanoparticles as High Relaxivity T-2-Contrast Agents for Magnetic Resonance Imaging. Advanced Functional Materials 2009, 19, 2319-2324.

(5) Carenza E.; Barceló, V.; Morancho, A.; Montaner, J.; Rosell, A.; Roig, A. Rapid synthesis of water-dispersible superparamagnetic iron oxide nanoparticles by a microwave-assisted route for safe labeling of endothelial progenitor cells. Acta Biomaterialia 2014, 10, 3775-3785.

(6) Xua, H.; Aguilar, Z. P.; Yange, L.; Kuang, M.; Duand, H.; Xionga Y.; Weia, H.: Wang, A. Antibody conjugated magnetic iron oxide nanoparticles for cancer cell separation in fresh whole blood. Biomaterials 2011, 32, 9758-9765.

(7) Carenza, E.; Barcelo, V.; Morancho, A.; Levander, L.; Boada, C.; Laromaine, A.; Roig, A.; Montaner, J.; Rosell, A. In vitro angiogenic performance and in vivo brain targeting of magnetized endothelial progenitor cells for neurorepair therapies. Nanomedicine 2014, 10, 225234.

(8) Vangijzegem, T.; Stanicki, D.; Laurent, S. Magnetic iron oxide nanoparticles for drug delivery: applications and characteristics. Expert Opinion in Drug Delivery 2019, (1) 16, 69-78.

(9) Coral, D. F.; Soto, P. A. ; Blank, V.; Veiga, A.; Spinelli, D.E.; Gonzalez, S,; Saracco, G.P.; Bab, M.A.; Muraca, D.; Setton-Avruj, P.C.; Roig, A, Roguin, L; Fernández van Raap, M. B. Nanoclusters of crystallographically aligned nanoparticles for magnetic thermotherapy: aqueous ferrofluid, agarose phantoms and ex vivo melanoma tumour assessment. Nanoscale, 2018, 10, 21262-21274.

(10) Mahmoudi, K.; Bouras, A.; Dominique, B; Robert, I.; Hadjipanayis, C. Magnetic hyperthermia therapy for the treatment of glioblastoma: a review of the therapy's history, efficacy and application in humans. Int. J. Hyperthermia 2018, 8, 1318-1328.

(11) Monopoli, M.; Åberg, C.; Salvati, A.; Dawson, K. Biomolecular coronas provide the biological identity of nanosized materials. Nature Nanotechnology 2012, (12) 7, 779-786. 
(12) Vilaseca, P.; Dawson, K.; Franzese, G. Understanding and modulating the competitive surface-adsorption of proteins through coarse-grained molecular dynamics simulations. Soft Matter 2013, (29) 9, 6978-6985.

(13) Ke, P. C.; Lin, S.; Parak, W. J.; Davis, T. P; Caruso, F. A decade of the protein corona. ACS Nano, 2017, 11, 11773-11776.

(14) Safi, M.; Courtois, J. Seigneuret, M.; Conjeaud, H.; Berret, J.-F. The effects of aggregation and protein corona on the cellular internalization of iron oxide nanoparticles. Biomaterials, 2011, (35) 32, 9353-9363.

(15) Xiao, W; Cao, H. The impact of protein corona on the behavior and targeting capability of nanoparticles-based delivery system. International Journal of Pharmaceutics, 2018, 552, 328339.

(16) Sakulkhu, U.; Maurizi, L.; Mahmoudi, M.; Motazacker, M.; Vries, M.; Gramoun, A.; Ollivier Beuzelin, M.-G.; Vallée, J.-P.; Rezaee, F.; Hofmann, H. Ex situ evaluation of the composition of protein corona of intravenously injected superparamagnetic nanoparticles in rats. Nanoscale, 2014, 6, 11439-11450.

(17) Tenzer, S. et al. Rapid formation of plasma protein corona critically affects nanoparticle pathophysiology. Nature Nanotechnol. 2013, 8, 772-781.

(18) Amiri, H.; Bordonali, L.; Lascialfari, A.; Wan, S.; Monopoli, M.P.; Lynch, I.; Laurent, S.; Mahmoudi, M. Protein corona affects the relaxivity and MRI contrast efficiency of magnetic nanoparticles. Nanoscale, 2013, 5, 8656-8665.

(19) Yallapu, M. M.; Chauhan, N.; Othman, S.F.; Khalilzad-Sharghi, V.; Ebeling, M. C.; Khan, S.; Jaggi, M.; Chauhan, S. C. Implications of protein corona on physico-chemical and biological properties of magnetic nanoparticles. Biomaterials, 2015, 46, 1-12.

(20) Stepien, G.; Moros, M.; Pérez-Hernández, M.; Mongel, M.; Gutiérrez, L.; Fratila, R. M.; de las Heras, M.; Menao Guillén, S.; Puente Lanzaroteo, J.J.; Solans, C.; Pardo, J.; Martínez de la Fuente, J. Effect of Surface Chemistry and Associated Protein Corona on the Long-Term Biodegradation of Iron Oxide Nanoparticles In Vivo. ACS Applied Materials \& Interfaces, 2018, (10) 5, 4548-4560.

(21) Oh, J. Y.; Kim, H. S.; Palanikumar, L.; Go, E. M.; Jana, B.; Park, S. A.; Kim, H. Y.; Kim, K.; Seo, J. K.; Kwak, S. K.; Kim, C.; Kang, S.; Ryu, J-H. Cloaking nanoparticles with protein corona shield for targeted drug delivery. Nature Communications 2018, 9, 4548-4557.

(22) Simon, J.; Müller, L. K.; Kokkinopoulou, M.; Lieberwirth, I.; Morsbach, S.; Landfesterb, K.; Mailänder, V. Exploiting the biomolecular corona: pre-coating of nanoparticles enables controlled cellular interactions. Nanoscale 2018, 10, 10731-10739.

(23) Mirshafiee V.; Kim R.; Park S.; Mahmoudi M.; Kraft M. Impact of protein pre-coating on the protein corona composition and nanoparticle cellular uptake. Biomaterials 2016, 75, 295-304. 
(24) Peng, Q.; Zhang, S.; Yang, Q.; Zhang, T.; Wei X.; Jiang, L.; Zhang, C.; Chen, Q.; Zhang, Z.; Lin, Y. Preformed albumin corona, a protective coating for nanoparticles based drug delivery system. Biomaterials 2013, 34, 8521-8530.

(25) Zaloga, J.; Pöttler, M.; Leitinger, G.; Friedrich, R.; Almer, G.; Lyer, S.; Baum, E.; Tietze, R.; Heimke-Brinck, R.; Mangge, H.; Dörje, F. L. G. Alexiou, C. Pharmaceutical formulation of HSA hybrid coated iron oxide nanoparticles for magnetic drug targeting. European Journal of Pharmaceutics and Biopharmaceutics 2016, 101, 152-158.

(26) Malaspina, D.; Pérez-Fuentes, L.; Drummond, C.; Bastos-González, D.; Faraudo, J. Protein-surface interactions at the nanoscale: Atomistic simulations with implicit solvent models. Current Opinion in Colloid \& Interface Science, 2019, 41, 40-49.

(27) Berman, H.; Henrick, K.; Nakamura, H.; Markley, J. The worldwide Protein Data Bank (wwPDB): ensuring a single, uniform archive of PDB data. Nucleic Acids Research, 2007, 35, D301-D303.

(28) Yu, S-M.; Perálvarez-Marín, A.; Minelli, C.; Faraudo, J.; Roig, A.; Laromaine, A. Albumincoated SPIONs: an experimental and theoretical evaluation of protein conformation, binding affinity and competition with serum proteins. Nanoscale, 2016, 8, 14393-14405.

(29) Yu, S.-M.; Gonzalez-Moragas, L.; Milla, M.; Kolovou, A.; Santarella-Mellwig, R.; Schwab, Y.; Laromaine, A.; Roig, A. Bio-identity and fate of albumin-coated SPIONs evaluated in cells and by the C. elegans model. Acta Biomaterialia, 2016, 43, 348-357.

(30) Mariam, J.; Sivakami, S.; Dongre, P. M. Albumin corona on nanoparticles - a strategic approach in drug delivery. Drug delivery, 2016, (8) 23, 2668-2676.

(31) Bolling C.; et al. Phase II study of MTX-HSA in combination with cisplatin as first linetreatment in patients with advanced or metastatic transitional cell carcinoma. Invest New Drugs, 2006, 4, 521-527.

(32) Kratz F. The first albumin-binding prodrug of doxorubicin to enter clinical trials. Expert Opin Investig Drugs 2007, 16, 855-866.

(33) Gradishar et al. Phase III trial of nanoparticle albumin-bound paclitaxel compared with polyethylated castor oil-based paclitaxel in women with breast cancer. J. Clin Oncol 2005, 23, 7794-7803.

(34) Yadav, R.; Pratik, S. Mechanistic investigation of domain specific unfolding of human serum albumin and the effect of sucrose. Protein Science, 2013, (11) 22, 1571-1581.

(35) Xiao, Q.; Huang, S.; Qi, Z.-D.; Zhou, B.; He, Z.-K.; Liu, Y. Conformation, thermodynamics and stoichiometry of HAS adsorbed to colloidal CdSe/ZnS quantum dots. Biochimica et Biophysica Acta, 2008, 1784, 1020-1027. 
(36) J.R. Lakowicz. Principles of Fluorescence Spectroscopy, 3rd ed, Plenum Press, New York, 2006, 277.

(37) Czub, M. P.; Venkataramany, B. S.; Majorek, K. A.; Handing, K. B.; Porebski, P. J.; Beeram, S. R; Suh, K; Woolfork, A. G.; Hage, D. S.; Shabalin, I. G.; Minor, W. Testosterone meets albumin - the molecular mechanism of sex hormone transport by serum albumins. Chemical Science, 2019, (6) 10, 1607-1618.

(38) Surgio, S.; Kashima, A.; Mochizuki, S.; Noda, M; Kobayashi, K. Crystal structure of human serum albumin at 2.5 A resolution. Protein Engineering, 1999, 12, 439-446.

(39) Sekar, G.; Haldar, M.; Thirumal, K., D.; George, P. D., C.; Mukherjee, A.; Chandrasekaran, $\mathrm{N}$. Exploring the interaction between iron oxide nanoparticles (IONPs) and Human serum albumin (HSA): Spectroscopic and docking studies. Journal of Molecular Liquids, 2017, 241, 793-800.

(40) Zhao,L.; Song, W.; Wang, J.; Yan, Y.; Chen, J.; Liu, R. Mechanism of Dimercaptosuccinic Acid Coated Superparamagnetic Iron Oxide Nanoparticles with Human Serum Albumin. J. Biochem. Molecular Toxicology, 2015, (12) 29, 579-586.

(41) Moore, T. L.; Rodriguez-Lorenzo, L.; Hirsch, V., Balog, S.; Urban, D.; Jud, C.; RothenRutishauser, B.; Lattuada, M.; Petri-Fink, A. Nanoparticle colloidal stability in cell culture media and impact on cellular interactions. Chemical Society Reviews, 2015, (17) 44, 6287-6305.

(42) Marieb, E. N.; Hoehn, K. Human anatomy \& physiology. Benjamin Cummings 2010.

(43) Jain, P. K.; Xiao, Y.; Walsworth, R.; Cohen, A. E. Surface Plasmon Resonance Enhanced Magneto-Optics (SuPREMO): Faraday Rotation Enhancement in Gold-Coated Iron Oxide Nanocrystals. Nano Lett., 2009, (4) 9, 1644-1650.

(44) http://cem.com/en/discover-sp-microwave-system-with-explorer-12-hybrid-autosampler.html.

(45) Humphrey, W.; Dalke, A.; Schulten, K. VMD: Visual molecular dynamics. Journal of Molecular Graphics, 1996, (14) 1, 33-38.

(46) Phillips, J.C.; Braun, R.; Wang, W.; Gumbart, J.; Tajkhorshid, E.; Villa, E.; Chipot, C.; Skeel, R.D.; Kalé, L.; Schulten, K. Scalable molecular dynamics with NAMD. J. Comput. Chem. 2005, (16) $26,1781-1802$.

(47) Tanner, D.; Chan, K.; Phillips, J.; Schulten, K. Tanner, D.; Chan, K.; Phillips, J.; Schulten, K. Parallel Generalized Born Implicit Solvent Calculations with NAMD. Journal of Chemical Theory and Computation, 2011, (11) 7, 3635-3642.

(48) Martínez, L.; Andrade, R.; Birgin, E.; Martínez, J. PACKMOL: A package for building initial configurations for molecular dynamics simulations. Journal of Computational Chemistry, 2009, 30 (13), 2157-2164. 
Table of Contents (TOC):

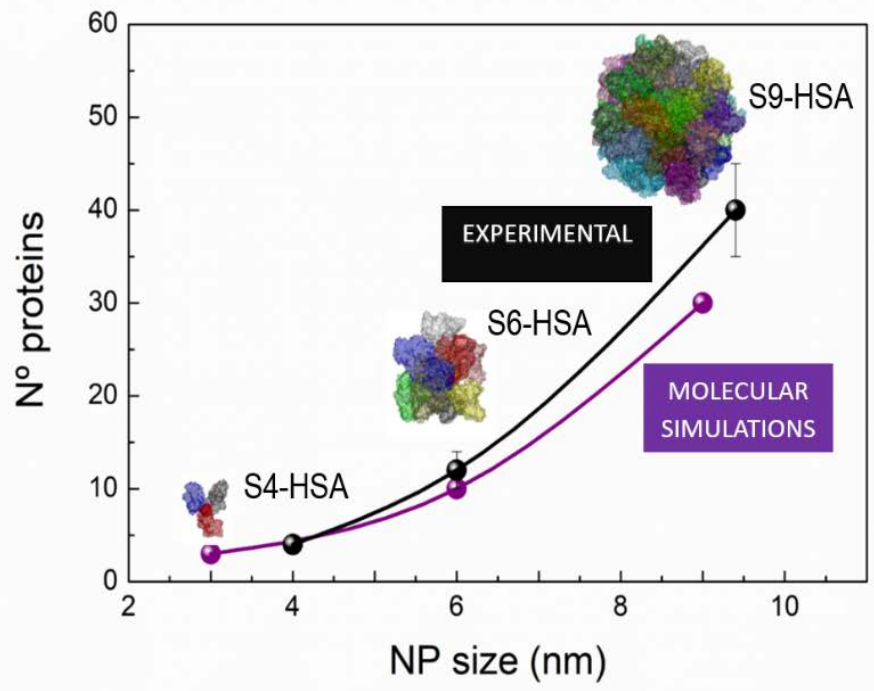

$\begin{array}{ccc}\mathrm{Fe}(\mu \mathrm{M}) & \mathrm{S} 6 & \mathrm{S6}-\mathrm{HSA} \\ 2 & & \\ 1.5 & & \\ 1 & \bigcirc & \\ 0.5 & \bigcirc & \\ 0 & 0 & \end{array}$

